\title{
OPTIMIZING THE CONTROL OF TECHNICAL PERFORMANCE OF FOREHAND STROKE AMONG 12-YEAR OLD TENNIS PLAYERS USING MARTIN'S SIGMA METHOD
}

\author{
M. Chalakov* \\ Department Language Learning and Information Technology, National Sports Academy \\ "Vassil Levski", Sofia, Bulgaria
}

\begin{abstract}
PURPOSE: The main purpose of this study is the optimization of the control over performing the forehand technique by 12-year old players using Martin's sigma method. MATERIAL AND METHODS: To achieve the goals of the study, we used video recording and analysis of the results of three tests applied in order to obtain information regarding the level of mastering the technique and the efficiency of the training process with 12-year old tennis players. The descriptive statistics and Martin's sigma method were used for data analysis. RESULTS: The obtained quantitative assessments allow comparing the achievements of players in each of the performed tests. CONCLUSIONS: This assessment model for forehand performance provides reliable quantitative feedback for managing and optimizing the training process in tennis with young players.
\end{abstract}

Key words: tennis, forehand, video analysis, descriptive statistics, normative table.

\section{INTRODUCTION}

Modern tennis is among the sports where the technical skills and player's achievements demand for a constant improvement and mastery. This requires the use of the latest methods and tools for control and assessment of the individual player's qualities.

Regarding the various game components - the ball strokes, it is believed that these motions are, from the biomechanical perspective, complex motions that require optimal levels of speed, power, spatiotemporal characteristics, and adequate perceptions and feelings from the performing athlete.

None of the above would be possible without developing modern information systems that enhance creating even better competitors regarding their technical performance. A good forehand technique can be developed and can turn into a serious "weapon" for all types of

\footnotetext{
*Correspondence to: Milen Chalakov, National Sports Academy "Vassil Levski", Department Language Learning and Information Technology, 1700, Sofia, Bulgaria, E-mail:

M.Chalakov@hotmail.com
}

players. This technique is often used to press the opponent and score a point (1).

As players improve, they determine by themselves the zone of attack (namely zones from the tennis court where they believe they could retreat after the backhand stroke in order to perform the attacking forehand). The players will also need to develop their specific footwork winch will allow them to perform those variants $(2,3)$.

As with most sports, in tennis diagnostics the player's technique and its improvement are major parts the training process (4). In this regard, using check-lists of various strokes (serve, ground stroke, volley, etc.) and the other tennis player's motions are going to be a common practice. These lists include verbal descriptions of various aspects and parameters that relate to the separate phases of the respective strokes and motions. Each stroke is divided into parts and steps, each of them contains a certain number of elements that define the major characteristics of the stroke. The coach or the sports pedagogue needs to write down systematically their quality assessment of the need for improvement opposite each item on the list and their views 
of the ways for further improvement $(5,6)$. Usually, coaches use check lists for each stroke as the main criterion for assessing, classifying, and improving tennis players. In addition to the preparation of checklists for a check-up the execution of the stroke, coaches also can take advantage of the use of statistical methods for measuring the strake distribution. Latest, the statistical methods and their characteristics are obvious practice in sport and physical education $(7,8)$. Most often, these characteristics are based on the development of standards for evaluation of results in sports-pedagogical tests. It is well known that the notion "norm" in sports science refers to the limit value of the result that allows the subject to be assigned to a certain classification group (6). The limit values are calculated based on the law of normal distribution. This property of the normal distribution is expressed in the socalled. "The rule of the three sigma's". Practically, this property of normal distribution is used to design standards using the sigma method, through mean (X) and standard deviation (S). The number of degrees, the verbal assessment and the percentage of cases that fall into them are determined by the researcher. (9)

It is worth considering that the process of assessing, diagnosing, and correction is completely different for beginner players. For them, efforts need to be a focus on improving the technique performance, while with elite tennis players, main achieving results is the goal. In addition, when working with elite players, the coach needs to pay closer personal attention to the athlete, which is not the case with beginner players.

\section{METHODS}

The main objective of this work is to optimize control over performing the forehand technique with 12-year old players and provide consistence, precision and speed of the ball.

To achieve this goal, the following tasks were formulated:

- Developing an information model and a table of norms, that allow for a quick, easy and objective assessment of each of the indicators in view and of the tennis player's condition at the current moment.

- Using kinematic analysis of strokes, to provide reliable quantitate feedback in the circle of managing and optimizing the training process in tennis.

- Applying tests that are close in content to the special preparation, training, and competitive actions, used in the course of a single's game.

- Approving the information system in practical conditions.

Thirty male and thirty female 12-year old tennis players took part in this study.

As a basis for the research, the three tests, which are verified in the NSA "Vasil Levski" (department "Football and Tennis"), sector "Tennis" were applied. They are extremely informative about the results achieved by the coaches in the training process and give a real picture of the learning process of forehand in tennis.

Test 1 - Consistency - All tennis players stroke 25 balls with forehand. The target is a 5 -meter diameter circle. The number of balls that landed in the circle was counted and considered as a score.

Test 2 - Precision - The tennis players perform 25 forehand strokes. The targets are two rectangles sized 2.5 by 3 meters and located at the two ends of the tennis court as one side of the rectangles bordered on the central line of the court. The number of balls that landed in the rectangles is counted.

Test 3 - Speed - Fifty forehand strokes performed, and the speed of the ball measured with speed radar. The speed of the precise strokes is considered.

To perform all tests, a tennis pitching machine was used.

The video recording was performed by means of Sony PJ740 camera at 50 frames per second. The camera was positioned perpendicularly to the stroke's direction and it was recorded whether each of the strokes hit the target area or not. For measuring the ball's speed, Speed Check - Personal Sports Radar, which measures speeds up to $300 \mathrm{~km} / \mathrm{h}$ with a permissible error of $\pm 0.16 \mathrm{~km} / \mathrm{h}$ were used.

The material that was video recorded was digitized and recorded as separate video files for each attempt of each of the players. The video-files were processed by means of video computer system for kinematic analysis Prof. Zdravko Arakchijski (10). Only the attempts that did not meet the precision, consistency, and linear ball speed criteria analysis were used for the complete. 
Statistical analysis

Descriptive statistics were used for summarizing a given data set. The measure of central tendency included the mean $(\mathrm{X})$ and measures of variability included the standard deviation ( $\mathrm{S})$, the minimum and maximum variables, coefficient of variation $(\mathrm{V} \%)$, range (R) and the kurtosis and skewness. The coefficient of variation (V\%) gives the information for the dispersion of the studied variable and offer the possibilities to compare the variation of the different indicators. It is accepted that the variation is low and simple is homogenous when the values are till $10-12 \%$; between 10 and $30 \%$ the simple is approximately homogenous and over $30 \%$ the variation of the indicator is high and simple is strongly non-homogenous.

The normal distribution is proving by the coefficient of skewness and kurtosis when the empirical data are $\leq$ of the theoretical depending of the number of the simple. The characteristics of the normal distribution have e big importance for developing the normative table using Martin's sigma method (Table 1).

Table 1. Shefko five level scale table

\begin{tabular}{|l|l|l|}
\hline Verbal assessment & $\mathrm{P} \%$ & Limits \\
\hline Low & $2,28 \%$ & Below $-2 . \mathrm{S}$ \\
\hline Below average & $13,59 \%$ & From $-2 . \mathrm{S}$ till $-1 . \mathrm{S}$ \\
\hline Average & $68,26 \%$ & From $-1 . \mathrm{S}$ till $+1 . \mathrm{S}$ \\
\hline Above average & $13,59 \%$ & From $+1 . \mathrm{S}$ till $+2 . \mathrm{S}$ \\
\hline High & $2,28 \%$ & Above $+2 . \mathrm{S}$ \\
\hline
\end{tabular}

The data were analysed following the standard procedures, using the statistical package for he Social Science (SPSS) v.19 for MAC (IBM, New York, NY, USA). The level of error was set at 5\%, considering the differences with a $\mathrm{p}$ $\leq 0.05$

\section{RESULTS}

The results obtained from the videorecordings were processed by means of descriptive statistics.
Throughout the video-recordings and tests, the mistakes when performing the strikes were analysed by the coach. The analysis was carried out in a video-room where for each individual child slow motion observation and stop-motion were used.

Table 2, Figure 1 and Figure 2 show the results of the precise strokes when performing the tests for boys and girls.

Table 2. Descriptive statistics for the tests (boys and girls)

\begin{tabular}{|c|c|c|c|c|c|c|}
\hline \multirow{2}{*}{$\begin{array}{l}\text { Statistical } \\
\text { indicators }\end{array}$} & \multicolumn{2}{|l|}{ Test 1} & \multicolumn{2}{|l|}{ Test 2} & \multicolumn{2}{|l|}{ Test 3} \\
\hline & Boys & Girls & Boys & Girls & Boys & Girls \\
\hline Mean & 19 & 18 & 18 & 17 & 104 & 94 \\
\hline S & 2.18 & 1.2 & 1.51 & 1.62 & 9.24 & 7.42 \\
\hline Ex & -0.97 & -0.54 & -0.73 & 0.10 & 0.65 & 0.35 \\
\hline As & -0.04 & -0.58 & 0.06 & -0.21 & 0.34 & -0.79 \\
\hline $\mathrm{R}$ & 8.00 & 4.00 & 6.00 & 7.00 & 43.00 & 30.00 \\
\hline $\mathrm{X} \min$ & 15.00 & 15.00 & 15.00 & 13.00 & 82.00 & 75.00 \\
\hline $\mathrm{X} \max$ & 23.00 & 19.00 & 21.00 & 20.00 & 125.00 & 105.00 \\
\hline $\mathrm{V} \%$ & 11.48 & 6.84 & 8.38 & 9.52 & 8.88 & 7.90 \\
\hline
\end{tabular}

It is evident, from the coefficients of variation $(\mathrm{V} \%)$, that the coefficient for all tests is within the range of $\mathrm{V}=12 \%$, which allows to consider the sample as highly homogeneous.

Considering the age of the tennis players can be stated that the results from test 1 are in accordance with the requirements for sports training with young tennis players. With this test, the need to develop the quality of consistence among 12-year old tennis players was proved. The good results that are displayed demonstrate a well planned and executed training process.

The information gathered from test 2 is directed towards the technical and tactical characteristics of the tennis player and control of their level of preparation. In order to manage the sports preparation, it is necessary 
to regulate the complex of loads (training and non-training) applied to the athlete based on the information received with the aim to achieve the goals set. This test also provides information about the motor skills of the participating young tennis players. When performing the test, it is not obligatory to hit consecutively the two rectangles. The participating player decides, according to his or her abilities now, where to apply the forehand stroke.

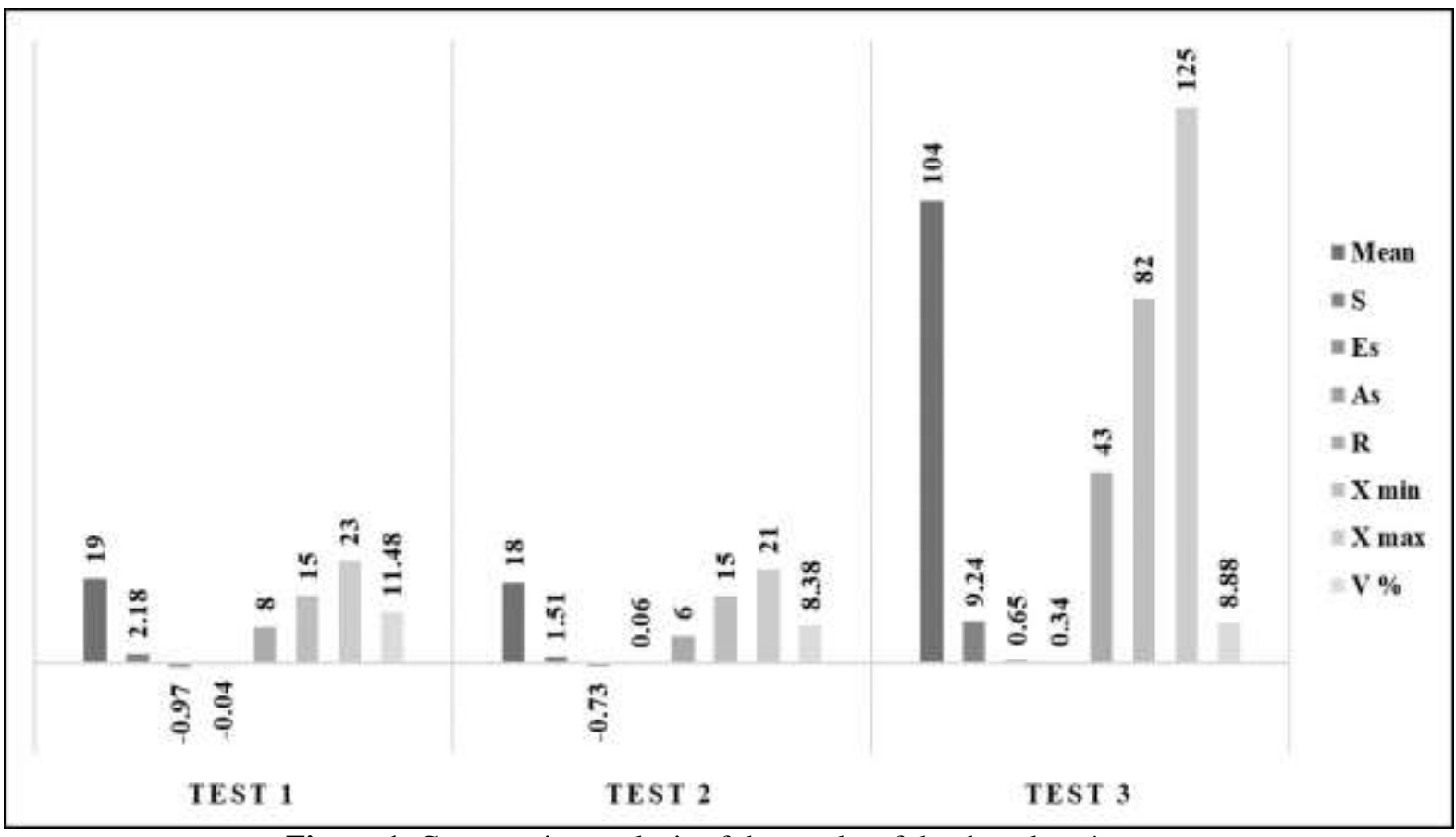

Figure 1. Comparative analysis of the results of the three boys' tests.

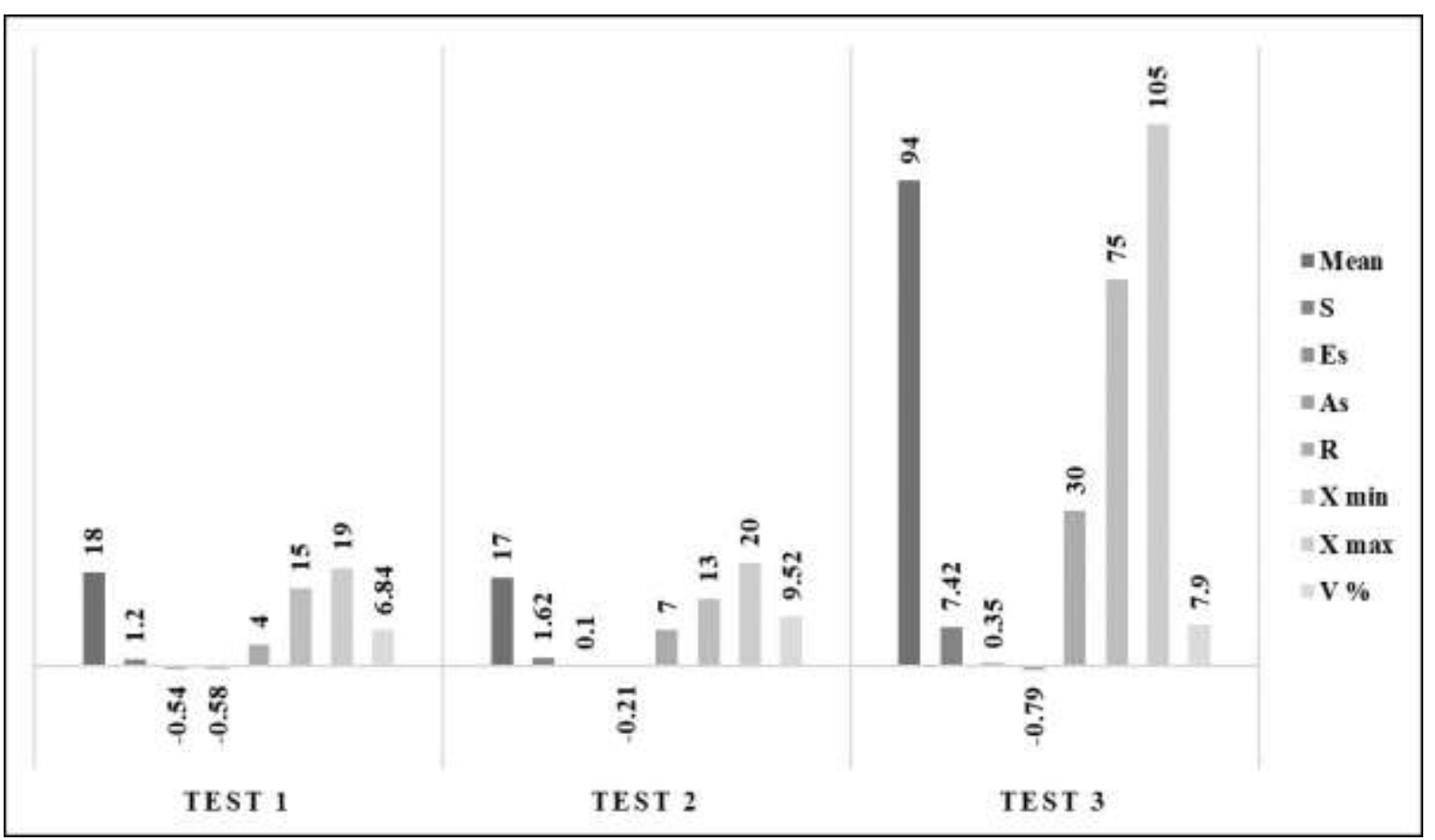

Figure 2. Comparative analysis of the results of the three girl' tests.

The precision norm requires a detailed study and analysis in order to discover the reasons for making the mistakes and to plan training methods for eliminating them.
The results from test 3 depend on all phases of the stroke - form the correct body posture when meeting the ball, through the swing with the racket, and to the precise delivery of the stroke against the ball. Low speeds give 
information about the mistakes concerning the mastering of the technique. Performing at a higher speed combined with the skills form the preceding tests limits the time and the opportunities of the opponent to perform a retour and at the same time contributes to making mistakes from the part of the opponent.

Based on the data from descriptive statistics, and the statistically important differences, the table (Table 3) for assessment and control of the measured features are created. The table is related on Martin's sigma method.

Table 3. Performance evaluation normative table

\begin{tabular}{|l|l|l|l|l|l|l|}
\hline \multirow{2}{*}{$\begin{array}{l}\text { Verbal evaluation } \\
\text { / Test }\end{array}$} & Test 1 & Test 2 & Test 3 \\
\cline { 2 - 7 } & Boys & Girls & Boys & Girls & Boys & Girls \\
\hline Excellent & Above 23 & Above 20 & Above 21 & Above 20 & Above 122 & Above 109 \\
\hline Very good & $21-22$ & $19-18$ & $20-19$ & $19-18$ & $121-113$ & $108-101$ \\
\hline Good & $19-20$ & $17-16$ & $18-17$ & $17-16$ & $112-104$ & $100-94$ \\
\hline Satisfactory & $17-18$ & $15-14$ & $16-15$ & $15-14$ & $103-95$ & $93-87$ \\
\hline Unsatisfactory & Under 17 & Under 14 & Under 15 & Under 14 & Under 95 & Under 87 \\
\hline
\end{tabular}

Tennis coaches and players aiming to constantly improve the technique of their strokes and believe that one of the key factors for that is the racket's speed increasing. The received data from our study show that the average speed reached for boys is $\mathrm{X}=104 \pm$ $9.24 \mathrm{~km} / \mathrm{h}$ and for girls is $X=94 \pm 7.42 \mathrm{~km} / \mathrm{h}$.

From the biomechanical point of view, inefficient motion and position of certain joints can reduce the speed of the ball and can even increase the risk of injuries. One of the most important principles used in achieving the maximum speed of the stroke is adding up speeds $(8,11,12)$. This means that motion needs to be initiated by the more powerful segments of the body, which should provide for achieving maximum speed at the end of the distal segment. This model of succession from the proximal to the distal end of the kinematic chain is the main characteristic of this principle and is described for many sports motions, including the ones of tennis (13-15). The forehand tennis stroke that was studied $(16,17)$ includes rotation along the longitudinal axis, an important factor that describes the complexity of tennis strokes, which was often neglected in previous studies of motions with an open kinematic chain Although the forehand stroke is the second most common element at profession-level matches (18), studies show that its kinematic structure is limited $(19,20)$.

The results from different studies $(21,22)$ indicate that at an early childhood age, the special characteristics of the motions are most easily perceived and internalized. Later follow the time and power characteristics, and further in time an optimum interaction among all independent factors can be expected, which in turn provides for a sustainable mastery and refinement of techniques. All of those, however, depend on the individual psychomotor qualities of children and requires purposeful efforts towards adequate adaptation of the training process for each child (23).

\section{CONCLUSION}

According to the coaches coaching children, the video recording and its analysis together with the tennis players are going to be an advantage for the training process and enhances the strong visual perception of the movement on the court and the execution of the phases of the strokes. In fact, tennis players see the correct motion (stroke) demonstrated by their coach, and then they look at their own performance at slow motion. The stroke analysis made by means of modern interactive methods, allows for easier perception by children. According to sports psychologies, the visual perception covers about $60 \%-70 \%$ of all perceptions of athletes.

For conclusion, based on the conducted study and applied statistical methods, the following conclusions can be drawn:

- The studied sample was highly homogeneous (V\% is till 10-12\%).

- Applying video analysis with tables of norms for control allows quick and objective assessment of achievement of each of the studied parameters and the training condition of the tennis player at the current moment.

- The qualitative assessments received allow comparing different players on each of the tests. This also permits to trace the level of 
development of each parameter for the purpose of future improvement.

- This model of assessment of forehand performance provides a reliable quantitative feedback for managing and optimizing the training process in tennis.

- The non-significant difference between the abilities of boys and girls to perform forehand stroke haven't been found.

- The long-year training influences in a positive way the studied parameters.

\section{REFERENCES}

1. Elliott, B., Reid, M., Whiteside, D., A Complete Guide to Evaluation, Treatment, and Rehabilitation, Biomechanics of Groundstrokes and Volleys, G.Di Giacomo et al. (eds.), Tennis Medicine. Springer International Publishing AG, pp. 17-42, 2018.

2. Hompson, J., Higgins, D., Gibson, T., CLUSTAL W: Improving the Sensitivity of Progressive Multiple Sequence Alignment through Sequence Weighting Position Specific Gap Penalties and Weight Matrix Choice, Nucleic Acids Research, 22(22): 4673-4690, 1994.

3. Crespo, M., Coaches Education Programme. Coach of beginner intermediate players (former ITF Level 1) Candidate Workbook. Biomechanics and technical analysis, ITF Coaching, International Tennis Federation, 13 p., 2008.

4. Fleising, G., Nicholls, R., Elliott, B., Escamilla, R., Kinematics used by world class tennis players to produce high velocity serves. Sports Biomechanics, 2(1): 51-64, 2003.

5. Bahamonde, R.E., Changes in angular momentum during the tennis serve. Journal of sports Sciences, 18 (8): 579 592, 2000.

6. Chanev, S., Yordanov, K., Assessment of the specific performance of 14-year-old basketball and handball players from Bulgarian sports schools. Sports and Science, 2: 170-176, 2017.

7. Antonov, A., Analysis and Detection of the Degrees and Direction of Correlations between Key Indicators of Physical Fitness of 10-12-year-old Hockey Players. Int. J. Bioautomation, 23(3): 303-314, 2019.

8. Bahamonde, R. E., Biomechanics of the forehand stroke. ITF Coaches Education Programme, ITF CSSR, 24: 6-8, 2001.
9. Pukelsheim, F., The Three Sigma Rule. The American Statistician, 48(2): 88-91, 1994.

10.Arakchiiski, Zdr., Video Computerized Automated Analysis System. Cinematographic methods for biomechanical analysis: Collected Papers, NSA - Press, Sofia, pp. 86-91, 2002.

11.Crespo, M., Miley, D., ITF Advanced Coaches Manual. International Tennis Federation, London, 334 p, 2007.

12.Karapetrova, R., Milashka, V., Lazarov, I., Stoykov, G., Stoykov, S., The Complex Speed-Power Capabilities of the DiscDiscuser, European Standards in Sport Education - Vratsa 2018, Collected Papers, AY AND BI, Vratsa, pp. 134-139, 2018.

13.Reid, M., Elliott, B., Crespo, M., Mechanics and learning practices associated with the tennis forehand: A review. Journal of Sports Science and Medicine, 12(2): 225-231, 2013.

14.Damm, L., Low, D., Richardson, A., Clarke, J., Carré, M., Dixon, S., The effects of surface traction characteristics on frictional demand and kinematics in tennis. Sports Biomechanics, 12(4): 389-402, 2013.

15.Edger, R. C., Optimizing Substitution Matrix Choice and Gap Parameters for Sequence Alignment, BMC Bioinformatics, 10: 396-405, 2009.

16.Henman, T., Vale, M., Junior Tennis: A Complete Coaching Manual for The Young Tennis Player. B.E.S. Publishing, England, 128 p., 2002.

17.Landlinger, J., Lindinger, S., Stöggl, T., Wagner H., Müller E. Key factors and timing patterns in the tennis forehand of different skill levels. Journal of Sports Science and Medicine, 9: 643-651, 2010.

18.Elliott, B.C., Takahashi, K., Noffal, G., The influence of the grip position on upper limb contributions to racket head velocity in a tennis forehand. Journal of Applied Biomechanics, 13(2): 182-196, 1997.

19.Johnson, C.D., McHugh, M.P., Performance demands of professional male tennis players. British Journal of Sports Medicine, 40(8): 696-699, 2006.

20.Kramer, T., Huijgen, B.C.H., ElferinkGemser, M.T., Visscher, C., Prediction of Tennis Performance in Junior Elite Tennis Players. Journal of Sports Science and Medicine, 16: 14-21, 2017.

21.Lyons, M., Al-Nakeeb, Y., Hankey, J., Nevill, A., The Effect of Moderate and High-Intensity Fatigue on Groundstroke 
Accuracy in Expert and Non-Expert Tennis Players. Journal of Sports Science and Medicine, 12: 298 - 308, 2013.

22.Marshall, R.N., Eliott, B.C., Long - axis rotation: the missing link in proximal to distal sequencing. Journal of sports Sciences, 18(4): 247 - 254, 2000.
23.Kwon, S., Pfister, R., Hager, R. L., Hunter, I., Seeley, M.K., Influence of Tennis Racquet Kinematics on Ball Topspin Angular Velocity and Accuracy during the Forehand Groundstroke. Journal of Sports Science and Medicine, 16: 505-513, 2017. 